ISSN 2078-774X (print)

\title{
Є. Є. ЧАЙКОВСЬКА
}

\section{КОМПЛЕКСНЕ МОДЕЛЮВАННЯ СУШИЛЬНОЇ УСТАНОВКИ У СКЛАДІ КОГЕНЕРАЦІЙНОЇ СИСТЕМИ}

\begin{abstract}
АНОТАЦІ Прогнозування зміни вологовмісту повітря в сушильній камері при вимірюванні температури повітря на вході в теплообмінник підігріву повітря дозволяє змінювати витрату повітря, шо нагрівається, на основі зміни частоти обертання електродвигуна повітряного вентилятора для забезпечення температурного режиму сушки в сушильній камері. Узгодження температурного та аеродинамічного режимів сушки деревини надає можливість, наприклад, при виробництві 5,8 тис. тонн пелет з деревини в рік здобути грошову економію при використанні пелетного палива до $40 \%$ та знизити собівартість виробництва енергї у складі когенераційної системи в межах $20-30 \%$.
\end{abstract}

Ключові слова: когенераційна установка, пелетне паливо, сушильна установка, вологовміст.

\section{E. CHAIKOVSKAYA}

\section{COMPLEX MODELLING DRYING PLANT IN THE COMPOSITION OF THE COGENERATION SYSTEM}

ABSTRACT The paper presents the architecture of a cogeneration system, the foundation of which is the dynamic subsystem. It includes a co-generation plant, drying plant, air heating heat exchanger, an air fan. Other units are units of discharge, charge, assessment of functional efficiency, which are consistent with the dynamic interaction subsystem. It is proposed an analytical evaluation of changes in the moisture content of the air in the drying chamber at an air temperature measured at the outlet of the drying chamber. The structural scheme of an complex modeling dryer is developed. Using the cyclic structure set functioning levels of dryer air temperature change at the inlet of the heat exchanger and heating the air leaving the heat exchanger which corresponds to a change of the equilibrium moisture content of wood in the drying chamber. The air flow entering the air-heating heat exchanger which corresponds to the level functioning the dryer is defined. The valid values change in the moisture content of the air in the drying chamber obtained They allow to change the flow rate of air supplied to the air preheating heat exchanger when the air temperature measured at the outlet of the drying chamber. Changing the air blower motor speed for changes in air flow provides thermal drying treatment in the drying chamber. Coordination of temperature and aerodynamic regimes of drying wood allows, for example, the production of 5.8 thousand tons of wood pellets per year to provide 860 apartments measuring $120 \mathrm{~m}^{2}$ pellet fuel that given the frequency regulation on electric air fan drying materials, provides gain saving money using pellet fuel for heating and hot water to $40 \%$ and reduce the cost of power generation and heat within (20-30) \% in in the conditions of the cogeneration system. Keywords: cogeneration plant, pellet fuel, drying plant, the moisture content.

\section{Вступ}

Використання біопалива для виробництва як електричної енергії, так і теплоти є достатньо стимулюючим фактором завдяки реалізації енергії за «зеленим тарифом» $[1,2]$. Основною характеристикою пелет, що можуть бути виготовлені з будьяких відходів деревообробної та сільськогосподарської промисловості, є вміст вологи, що не повинен перевищувати (10-12)\%. Сира ж деревина, наприклад, може містити близько 50 \% води. Вимірювання температури та вологості повітря як сушильного агенту, вологості деревини, що висушується, мають не завжди достовірне використання у зв'язку із складністю вимірів, що унеможливлює упереджений вплив на зміну параметрів сушки для забезпечення безперервного виробництва пелетного палива. Витрати ж на сушку матеріалу складають до $25 \%$ від загальних витрат. 3 метою енергозбереження підтримка температурного та аеродинамічного режимів сушки повинна відбуватись в узгодженій взаємодії, що можливо здобути з використанням когенераційних технологій, які мають у своєму складі первинний двигун, електро- генератор, систему утилізації теплоти, систему контролю й управління. Засоби удосконалення сушильних технологій деревини базуються як на інтенсифікації процесів теплообміну в сушильній камері, так і на удосконаленні систем управління процесом сушки. В роботі [3], наприклад, визначено перевагу сушильним установкам 3 механічною активацією матеріалу, що дозволяє збільшити питому напругу сушки за випарюваною вологістю, але за рахунок додаткових витрат на електричну енергію. В роботі [4] встановлено вплив конструктивних параметрів сушильної камери на якість сушки, але при вимірюванні параметрів сушки в сушильній камері. В роботі [5] визначено вплив режимних параметрів сушки на якість сушки, але без можливості узгодження температурного та аеродинамічного режимів сушіння матеріалу. В роботі [6] видані рекомендації щодо інтенсифікації теплообміну в сушильній камері, але без можливості їх використання в реальних умовах функціонування сушильної установки. Найважливішим показником сушки сировини при виробництві пелетного палива $є$ потужність сушки, що відтворює кількісне відношення вологості сировини до іiі рівно- 
важної вологості. Рівноважна вологість деревини середнє значення між сорбцією та десорбцією деревини, а при використанні сировини щодо виробництва пелетного палива практично дорівнює його стійкої вологості, яка залежить від температури повітря та його відносної вологості. Потужність сушки має бути більшою за одиницю [7]. Для підтримки потужності сушки деревини використовують коштовні експертні діагностичні системи, що базуються на вимірюванні температури повітря та його вологості в сушильній камері при вимірюванні вологості деревини. Складність вимірів при не можливості використання у взаємній єдності може привести до зворотного процесу накопичення вологи сушильним матеріалом чи припинення процесу сушки сировини [8, 9]. Для уникнення негативних явищ сушки необхідно прогнозувати зміну вологості повітря при вимірюванні температури повітря на виході із сушильної камери, що надходить в теплообмінник підігріву, щодо зміни рівня потужності сушки. Цим обгрунтовується актуальність даної роботи.

\section{Мета роботи}

Мета роботи - здобути еталонну оцінку зміни вологовмісту повітря в залежності від рівноважної вологості деревини для підтримки температурного та аеродинамічного режимів сушки. Поставлена мета може бути досягнена при виконанні таких задач:

- обгрунтувати необхідність комплексного моделювання динаміки сушильної установки, що включає сушильну камеру, теплообмінник для підігріву повітря та повітряний вентилятор;

- запропонувати архітектуру когенераційної системи, що має у своєму складі основу - динамічну підсистему, яка включає когенераційну установку, сушильну камеру. теплообмінник для підігріву повітря. повітряний вентилятор та блоки розряду, заряду, оцінки функціональної ефективності, що знаходяться в узгодженій взаємодії з динамічною підсистемою;

- виконати математичне моделювання динаміки сушильної установки щодо прогнозування зміни вологовмісту повітря при вимірюванні температури повітря на виході із сушильної камери;

- запропонувати структурну схему для здобуття еталонної інформації на основі комплексного моделювання у складі когенераційної системи;

- виконати комплексне математичне моделювання сушильної установки щодо визначення параметрів теплообміну та поверхні теплообміну теплообмінника підігріву повітря для встановлених рівнів функціонування сушильної установки згідно зміни витрати повітря;

- здобути еталонну оцінку зміни вологовмісту повітря в залежності від рівноважної вологості сировини для підтримки температурного та аеродинамічного режимів сушки;

- оцінити практичну значущість здобутих результатів.

\section{Комплексне моделювання у складі когенераційної системи}

На основі методологічного та математичного обгрунтування архітектури технологічних систем [2] запропонована архітектура когенераційної системи, основою якої $\epsilon$ інтегрована динамічна підсистема - (когенераційна установка, сушильна камера, теплообмінник для підігріву повітря, повітряний вентилятор) та блоки розряду, заряду, оцінки функціональної ефективності, що знаходяться в узгодженій взаємодії $з$ динамічною підсистемою (рис. 1).

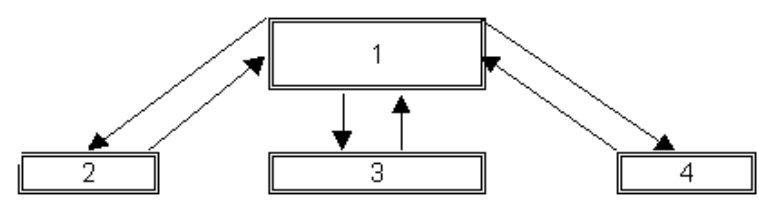

Рис. 1 - Архітектура когенераційної системи: 1 - динамічна підсистема (когенераційна установка, сушильна камера, теплообмінник для підігріву повітря, повітряний вентилятор); 2 - блок розряду; 3 - блок заряду; 4 - блок очінки функціональної ефективності

Математичне обгрунтування архітектури когенераційної системи:

$$
\begin{gathered}
C S=\left(\left(D \left(P ( \tau ) \left(x_{0}(\tau), x_{1}(\tau), x_{2}(\tau), f(\tau),\right.\right.\right.\right. \\
K(\tau), y(\tau), d(\tau))), Z(\tau), P(\tau)), R(\tau), \\
\left(P_{i}(\tau)\left(x_{1}(\tau), f_{i}(\tau), K_{i}(\tau), y_{i}(\tau)\right)\right),
\end{gathered}
$$

де $C S$ - когенераційна система; $D$ - динамічна підсистема (когенераційна установка, сушильна камера, теплообмінник для підігріву повітря, повітряний вентилятор); $P$ - властивості елементів когенераційної системи; $x$ - впливи; $f$ - параметри, що діагностуються; $K$ - коефіцієнти математичного опису; $y$ - вихідні параметри; $d$ - динамічні параметри; $R$-логічні відносини в $C S ; \tau-$ час, с. Індекси: $i$ - число елементів когенераційної системи; $0,1,2$ - початковий стаціонарний режим, зовнішній, внутрішній характер впливів.

Основою для підтримки температурного та аеродинамічного режимів сушки щодо встановлення зміни витрати повітря при вимірюванні температури повітря на виході із сушильної камери $\epsilon$ математична модель динаміки сушильної установки. Система нелінійних диференціальних рівнянь включає рівняння стану як фізичну модель теплообмінника, рівняння енергії передавального середовища - теплоносія, що гріє, від когенераційної 
установки, рівняння енергії сприймаючого середовища - повітря, в якому зміна вологовмісту повітря оцінена як у часі, так і вздовж просторової координати осі теплообмінника для підігріву повітря, що співпадає 3 напрямком потоку руху середовища, та рівняння теплового балансу для стінки теплообмінника. В результаті реалізації математичної моделі отримана передатна функція за каналом: «вологовміст повітря - витрата повітря» [10]:

$$
W_{w-G_{\mathrm{B} 1}}=\frac{K_{\mathrm{B}}(\beta-1)}{L_{\mathrm{B}} K_{w} \beta \gamma}\left(1-e^{-\gamma 1 \xi}\right),
$$

де $K_{\text {в }}=\frac{m\left(\theta_{0}-\sigma_{0}\right)}{G_{\text {в } 0}} ; \beta=T_{\mathrm{M}} S+\varepsilon^{*}+1 ; T_{\mathrm{M}}=\frac{g_{\mathrm{M}} C_{\mathrm{M}}}{\alpha_{\mathrm{B} 0} h_{\mathrm{B} 0}} ;$

$$
\begin{gathered}
\varepsilon^{*}=\varepsilon\left(1-L_{s}^{*}\right) ; \varepsilon=\frac{\alpha_{30} h_{30}}{\alpha_{\mathrm{B} 0} h_{\mathrm{B} 0}} ; L_{s}^{*}=\frac{1}{L_{3}+1} ; \\
L_{3}=\frac{G_{3} C_{3}}{\alpha_{30} h_{30}} ; \gamma_{1}=T_{\mathrm{B}} S ; T_{\mathrm{B}}=\frac{g_{\mathrm{B}} C_{\mathrm{B}}}{\alpha_{\mathrm{B} 0} h_{\mathrm{B} 0}} ; \xi=\frac{z}{L_{\mathrm{B}}} \\
L_{\mathrm{B}}=\frac{G_{\mathrm{B}} C_{\mathrm{B}}}{\alpha_{\mathrm{B} 0} h_{\mathrm{B} 0}} ; K_{w}=\frac{\partial i}{\partial w} / \frac{\partial i}{\partial t} ; \gamma=\frac{T_{\mathrm{B}} S}{L_{\mathrm{B}}},
\end{gathered}
$$

де $t, \sigma, \theta$ - температура повітря, температура теплоносія, що гріє, температура стінки теплообмінника, К, відповідно; $G$ - витрата речовини, кг/с; $C$ - питома теплоємність, кДж/(кг·К); $i$ - ентальпія робочого тіла, кДж/кг; $w$ - вологовміст повітря; $\alpha$ - коефіцієнт тепловіддачі, кВт/( $\left.{ }^{2} \cdot \mathrm{K}\right) ; h$ - питома поверхня, м²/м; $g$ - питома маса речовини, кг/м; $z$ - координата довжини теплообмінника, м; $T_{\mathrm{B}}, T_{\mathrm{M}}$ - постійні часу, що характеризують теплову акумулюючу здатність повітря, метала, с, відповідно; $m$ - показник залежності коефіцієнта тепловіддачі від витрати; $S$ - параметр перетворення Лапласа; $S=\omega j ; \omega-$ частота, 1/с. Індекси: в - внутрішній потік - повітря; м - металева стінка; 3 - зовнішній потік - теплоносій, що гріє; $w$ - вологовміст повітря; 0, 1 - початкові умови, вхід в теплообмінник, відповідно.

Для використання передатної функції у складі комплексного математичного моделювання динаміки сушильної установки, виділено дійсну частину, $O(\omega)$, що має такий вид

$$
O(\omega)=\left(C_{1} L_{1}-D_{1} M_{1}\right)\left(K_{\text {в }} / K_{w}\right) .
$$

Для одержання коефіцієнтів у складі дійсної частини $O(\omega)$ здобуто такі вирази:

$$
\begin{gathered}
C_{1}=\frac{A_{1} A_{2}+B_{1} B_{2}}{A_{2}{ }^{2}+B_{2}{ }^{2}} ; L_{1}=1-\cos \left(-\xi T_{\mathrm{B}} \omega\right) ; \\
D_{1}=\frac{A_{2} B_{1}-A_{1} B_{2}}{A_{2}{ }^{2}+B_{2}{ }^{2}} ; M_{1}=1-\sin \left(-\xi T_{\mathrm{B}} \omega\right), \\
\text { де } \quad A_{1}=\varepsilon^{*}-T_{\mathrm{B}} T_{\mathrm{M}} \omega^{2} ; A_{2}=-T_{\mathrm{B}} T_{\mathrm{M}} \omega^{2} ; \\
B_{1}=T_{\mathrm{M}} \omega ; B_{2}=T_{\mathrm{B}} \omega(\varepsilon+1) .
\end{gathered}
$$

Температура поділяючої стінки $\theta$, що входить до складу коефіцієнта $K_{\text {в }}$

$$
\theta=\left[\frac{\alpha_{\mathrm{B}}\left(\sigma_{1}+\sigma_{2}\right)}{2}+\frac{A\left(t_{1}+t_{2}\right)}{2}\right] /\left(\alpha_{\mathrm{B}}+A\right),
$$

де $\sigma_{1}, \sigma_{2}$ - температура теплоносія, що гріє, на вході, та на виході $з$ теплообмінника, К, відповідно; $t_{1}, t_{2}$ - температура повітря на виході з сушильної камери та на вході в сушильну камеру, К, відповідно: $\alpha$ - коефіцієнт тепловіддачі, кВт/( $\left.\mathrm{м}^{2} \cdot \mathrm{K}\right)$; Індекс: в - внутрішній потік - повітря.

$$
A=\frac{1}{\frac{\delta_{\mathrm{M}}}{\lambda_{\mathrm{M}}}+\frac{1}{\alpha_{3}}},
$$

де $\delta$ - товщина стінки теплообмінника, м; $\alpha$ - коефіцієнт тепловіддачі, кВт/( $\left.\mathrm{M}^{2} \cdot \mathrm{K}\right) ; \lambda$ - теплопровідність металу стінки теплообмінника, кВт/(м·К). Індекс: 3 - зовнішній потік - теплоносій, що гріє.

3 використанням інтеграла переходу з частотної області до області часу зміна вологовмісту повітря як за часом, так і вздовж просторової координати осі теплообмінника для підігріву повітря визначена так

$$
w(\tau, z)=\frac{1}{2 \pi} \int_{0}^{\infty} O(\omega) \sin (\tau \omega / \omega) d \omega,
$$

де $\tau$ - час, c.

Для комплексного моделювання динаміки сушильної установки запропоновано структурну схему з використанням, наприклад, здобутих вихідних даних щодо виробництва 680 кг/добу пелетного палива (рис. 2).

В межах зменшення вологості сировини 3 $40 \%$ до $12 \%$ встановлено перший, другий, третій рівні функціонування сушильної установки згідно зміні рівноважної вологості повітря в сушильній камері: $20 \%, 15 \%, 12 \%$. Завдяки запропонованій структурній схемі (рис. 2) в межах визначеної циклічної структури встановлені наступні рівні зміни температури повітря на вході в теплообмінник та на виході 3 теплообмінника: перший рівень: (55-85) ${ }^{\circ} \mathrm{C}$; другий рівень: $(52,6-80,8){ }^{\circ} \mathrm{C}$; третій рівень: (51,3-77) ${ }^{\circ} \mathrm{C}$, та рівні зміни витрати повітря; 1,8 кг/с, 1,68 кг/с, 1,65 кг/с, що відповідають зміні рівноважної вологості повітря $20 \%, 15 \%$, $12 \%$. Результати комплексного моделювання динаміки сушильної установки представлені в табл. 1-3 та на рис. 3.

Підтримку функціонування сушильної установки у складі когенераційної системи забезпечує повітряний вентилятор для можливості частотного регулювання зміни витрати повітря щодо встановлення температури повітря на вході в сушильну камеру з ціллю підтримки потужності сушки матеріалу. 


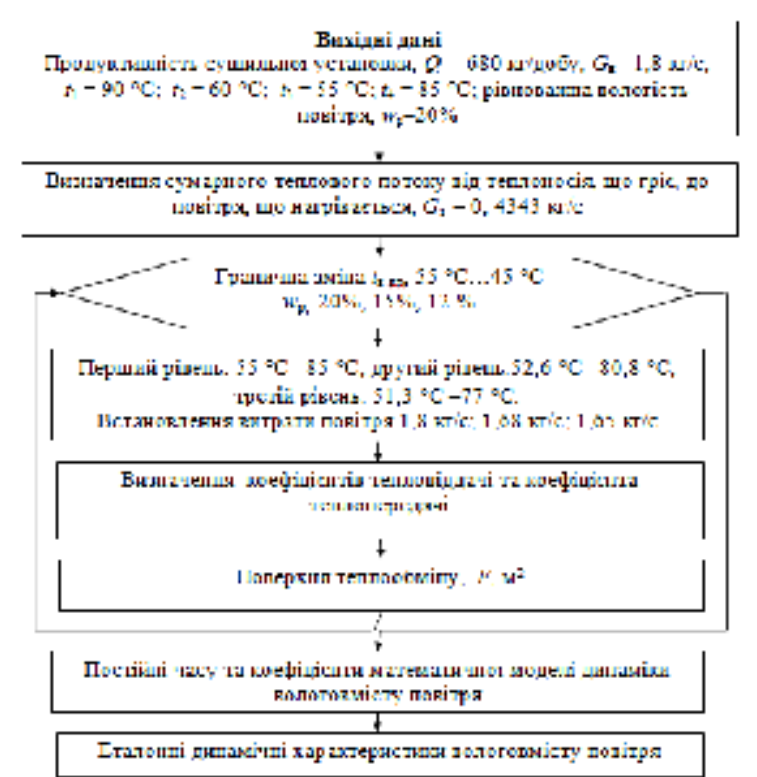

Рис. 2 - Структурна схема комплексного моделювання сушильної установки: $G_{3}, G_{6 .}-$ витрата теплоносія, щчо гріє, повітря, кг/с, відповідно; $t_{1}, t_{2}$ - температура теплоносія, щуо гріє на вході в теплообмінник та на виході з теплообмінника, $K$, відповідно; $t_{3}, t_{4}$ - температура повітря на вході в теплообмінник та на виход $i$ з теплообмінника, $K$, відповідно $t_{в в-}$ - температура повітря на вході в теплообмінник, $K$

Таблиця 1 - Параметри теплообміну в теплообміннику підігріву повітря

\begin{tabular}{|l|c|c|c|}
\hline \multirow{2}{*}{$\begin{array}{c}\text { Рівні } \\
\text { функціонування }\end{array}$} & $\begin{array}{c}|c| \\
\alpha_{3}, \\
\mathrm{BT} /\left(\mathrm{M}^{2} \cdot \mathrm{K}\right)\end{array}$ & $\begin{array}{c}\alpha_{\mathrm{B}}, \\
\mathrm{B} /\left(\mathrm{M}^{2} \cdot \mathrm{K}\right)\end{array}$ & $\begin{array}{c}k, \\
\mathrm{BT} /\left(\mathrm{M}^{2} \cdot \mathrm{K}\right)\end{array}$ \\
\hline Перший рівень & 3050,67 & 254,33 & 233,05 \\
\hline Другий рівень & 2912,86 & 242,84 & 222,59 \\
\hline Третій рівень & 2877,91 & 239,92 & 219,94 \\
\hline
\end{tabular}

Примітка: $\alpha_{3}$ - коефіцієнт тепловіддачі від теплоносія, що гріє до стінки теплообмінника, Вт/( $\left.{ }^{2} \cdot \mathrm{K}\right) ; \alpha_{\mathrm{B}}-$ коефіцієнт тепловіддачі від стінки теплообмінника до повіт-

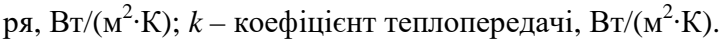

Таблиця 2 - Постійні часу та коефіцієнти математичної моделі динаміки теплообмінника

\begin{tabular}{|l|c|c|c|c|}
\hline $\begin{array}{c}\text { Рівні } \\
\text { функціонування }\end{array}$ & $T_{\mathrm{B}}, \mathrm{c}$ & $T_{\mathrm{M}}, \mathrm{c}$ & $\varepsilon$ & $\zeta$ \\
\hline Перший & 0,0048 & 0,6149 & 14,547 & 0,146 \\
\hline Другий & 0,0050 & 0,6440 & 14,547 & 0,136 \\
\hline Третій & 0,0051 & 0,6518 & 14,547 & 0,134 \\
\hline
\end{tabular}

Таблиця 3 -Коефіцієнти математичної моделі динаміки теплообмінника

\begin{tabular}{|l|c|c|c|c|}
\hline $\begin{array}{c}\text { Рівні } \\
\text { функціонування }\end{array}$ & $L_{3}, \mathrm{M}$ & $L_{\mathrm{B}}, \mathrm{M}$ & $L_{3}{ }^{*}, 1 / \mathrm{M}$ & $K_{w}$ \\
\hline Перший & 33,26 & 483,89 & 0,029 & $-0,9646$ \\
\hline Другий & 32,51 & 472,99 & 0,029 & $-1,2848$ \\
\hline Третій & 32,32 & 470,19 & 0,030 & $-1,6060$ \\
\hline
\end{tabular}

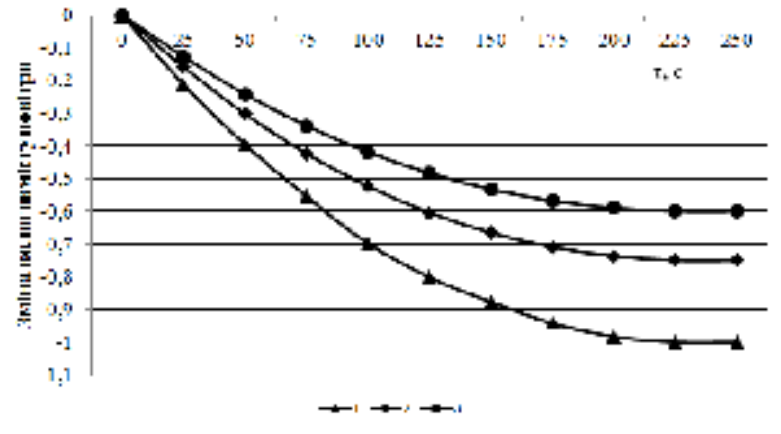

Рис. 3 - Допуски на граничну працездатність сушильної установки для встановлених рівнів функціонування: 1, 2, 3 - еталони підтримки рівноважної вологості повітря $20 \%, 15 \%, 12 \%$, відповідно

\section{Обговорення результатів}

В результаті проведених досліджень у складі запропонованої когенераційної системи виконано комплексне моделювання сушильної установки, що включає сушильну камеру, теплообмінник для підігріву повітря, повітряний вентилятор. 3 цією ціллю здобута аналітична оцінка зміни вологовмісту повітря в сушильній камері в зв'язку із недостовірним використанням виміру. Розроблена структурна схема для здобуття еталонної оцінки зміни вологовмісту повітря в сушильній камері при зміні температури повітря на виході із сушильної камери, що вимірюється, для встановлених рівнів функціонування сушильної установки згідно зміні рівноважної вологості повітря. У складі циклічної структури запропонованої структурної схеми встановлено рівні зміни температури повітря на вході в теплообмінник підігріву повітря та виході з теплообмінника та рівні зміні витрати повітря, що відповідають зміні рівноважної вологості повітря в сушильній камері. Визначено параметри теплообміну теплообмінника для підігріву повітря, поверхню теплообміну теплообмінника, що вдовольняють встановленим рівням функціонування сушильної установки. Здобуто еталонну оцінку зміни вологовмісту повітря в залежності від рівноважної вологості деревини щодо зміни частоти обертання електродвигуна повітряного вентилятора для підтримки функціонування сушильної установки. Запланована апробація здобутих результатів в умовах когенераційних систем з використанням виробництва пелетного палива різної потужності.

\section{Висновки}

\section{В результаті проведених досліджень} встановлено, що:

1) Виробництво пелетного палива потребує розробки комплексного моделювання динаміки сушильної установки, що включає сушильну ка- 
меру, теплообмінник для підігріву повітря, повітряний вентилятор для здобуття еталонної оцінки зміни вологовмісту повітря в сушильній камері щодо підтримки температурного та аеродинамічного режимів сушки деревини на основі зміни частоти обертання електродвигуна повітряного вентилятора.

2)Запропонована архітектура когенераційної системи, що має у своєму складі основу - динамічну підсистему, яка включає когенераційну установку, сушильну камеру, теплообмінник для підігріву повітря, повітряний вентилятор та блоки розряду, заряду, оцінки функціональної ефективності, що знаходяться в узгодженій взаємодії 3 динамічною підсистемою.

3) Виконано математичне моделювання динаміки сушильної установки щодо прогнозування зміни вологовмісту повітря при вимірюванні температури повітря на виході із сушильної камери.

4) Запропонована структурна схема комплексного моделювання динаміки сушильної установки щодо здобуття еталонної оцінки зміни вологовмісту повітря в сушильній камері при зміні температури повітря на виході із сушильної камери, що вимірюється.

5) Встановлено рівні зміни температури повітря на вході в теплообмінник підігріву повітря та на виході з теплообмінника, що відповідають зміні рівноважної вологості повітря; встановлено рівні зміни витрати повітря що підтримують зміну рівноважної вологості повітря.

6) Визначено параметри теплообміну теплообмінника для підігріву повітря, поверхню теплообміну теплообмінника, що вдовольняють встановленим рівням функціонування сушильної установки.

7) Здобута еталонна оцінка зміни вологовмісту повітря в сушильній камері в залежності від рівноважної вологості сировини для підтримки температурного та аеродинамічного режимів сушки.

8) Узгодження температурного та аеродинамічного режимів сушки деревини надає можливість, наприклад, при виробництві 5,8 тис. тонн пелет 3 деревини в рік здобути грошову економію при використанні пелетного палива до $40 \%$ та знизити собівартість виробництва енергії у складі когенераційної системи в межах (20-30) \% [10].

\section{Список літератури}

1 Гелетуха, Г. Г. Биоэнергетика в Украине: современное состояние и перспективы развития. Часть 2 [Текст] / Г. Г. Гелетуха, Т. А. Железная, П. П. Кучерук, Е. Н. Олейник, А. В. Трибой // Промышленная теплотехника. - 2015. - Т. 37, № 3. C. 65-73. - ISSN ISSN 0204-3602.

2 Чайковська, Є. С. Розробка енергозберігаючої технології функціонування біогазової установки у скла- ді когенераційної системи [Текст] / Є. Є. Чайковська // Восточно-Европейский журнал передовых технологий. -2015 . - Т. 3, № 8(75). - С. 47-53. - ISSN ISSN 1729-3774. - doi: 10.15587/17294061.2015.442522.

3 Трошин, А. Г. Развитие процессов и оборудования для производства топливных брикетов из биомассы [Текст] / А. Г. Трошин, В. Ф. Моисеев, И. А. Тельнов， С. И. Завинский // ВосточноЕвропейский журнал передовых технологий. -2010. - № 8/45(3). - C. 36-40. - ISSN ISSN 1729-3774.

4 Bhattarai, Sujala. Simulation Study for Pneumatic Conveying Drying of Sawdust for Pellet Production [Text] / Sujala Bhattarai, Jae-Heun Oh, Seung-Hee Euh, Dae Hyun Kim, Liang Yu // Drying Technology. - 2014. - Vol. 32. - P. 1142-1156. - ISSN ISSN 07373937 - doi: 10.1080/07373937.2014.884575.

5 Laurila, Jussi. Compression drying of energy wood [Text] / Jussi Laurila, Havimo Mikko, Lauhanen Risto // Fuel Processing Technology. - 2014. - Vol. 124. P. 286-289. - ISSN ISSN 0378-3820. - doi: 10.1016/j.fuproc.2014.03.016.

6 Yuping, Liu. Application of the self-heat recuperation technology for energy saving in biomass drying system [Text] / Liu Yuping, Aziz Muhammad, Kansha Yasuki, Bhattacharya Sankar, Tsutsumi Atsushi // Fuel Processing Technology. - 2014. - Vol. 117. - P. 66-74. - ISSN ISSN 0378-3820. $\quad$ - doi: 10.1016/j.fuproc.2013.02.007.

7 Wang, Hai-tao. Study of Immune PID Controller for Wood Drying System [Text] / Hai-tao Wang, He-ming Jia // 2013 International Conference on Communication Systems and Network Technologies. - 2013. - P. 827831. - ISSN ISBN 1-4673-5603-9. - doi: $10.1109 /$ csnt.2013.176.

8 Zhongfu, Tian. Research on control system of wood drying based on BP Neural Network [Text] / Tian Zhongfu, Li Yuehua // Proceedings 2013 International Conference on Mechatronic Sciences, Electric Engineering and Computer (MEC). - 2013. - P. 36-38. - ISBN 4-4799-2564-3. - doi: 10.1109/mec.2013.6885046.

9 Perre, Patrick. Drying of Wood: Principles and Practices [Text] / Patrick Perre, Roger Keey // Handbook of Industrial Drying. - 2014. - P. 797-846. - ISSN ISBN 978-1-4665-9665-8. - doi: 10.1201/b17208-44.

10 Чайковська, Є. Є. Розробка методу підтримки функціонування сушильної установки у складі когенераційної системи [Текст] / Є. Є. Чайковська // Технологический аудит и резервы производства. -2015 . - № 5/7(25). - C. 62-67. - ISSN ISSN 2312-8372. doi: $10.15587 / 2312-8372.2015 .51520$.

\section{Bibliography (transliterated)}

1 Heletuha, H. H., Gelieznaia, T. A., Kuchtruk, P. P., Olienic, E. N. and Triboi, A. B. (2015), "Biojenergetika v Ukraine: sovremennoe sostojanie i perspektivy razvitija. Chast' 2 [Bioenergy in Ukraine: Current State and Prospects for Development. Part 2.]", Promyshlennaja teplotehnika [Industrial Heat Engineering], no. 3(37), pp. 65-73, ISSN 0204-3602.

2 Chaikovskaya, E. E. (2015), "Rozrobka energozberigajuchoi' tehnologii' funkcionuvannja biogazovoi' ustanovky u skladi ko-generacijnoi' systemy [Development of energy-operation of biogas plant as part of a cogeneration system]", Vostochno-Evropejskij zhurnal 
peredovyh tehnologij [Eastern-European Journal of Enterprise Technologies], no. 3/8(75), pp. 47-53, ISSN 1729-3774, doi: 10.15587/1729-4061.2015.442522.

3 Trohin, A. H., Moisiev, V. F., Telnov, I. A. and Zavinski, S. I. (2010), "Razvitie processov i oborudovanija dlja proizvodstva toplivnyh briketov iz biomassy [Development of processes and equipment for the production of fuel pellets from biomass]", VostochnoEvropejskij zhurnal peredovyh tehnologij [EasternEuropean Journal of Enterprise Technologies], no. 8/45(3), pp. 36-40, ISSN 1729-3774.

4 Bhattarai Sujala, Jae-Heun Oh, Seung-Hee Euh, Dae Hyun Kim and Liang Yu (2014), "Simulation Study for Pneumatic Conveying Drying of Sawdust for Pellet Production", Drying Technology, no. 32, pp. 1142-1156, ISSN 0737-3937, doi: 10.1080/07373937.2014.884575.

5 Jussi Laurila, Havimo Mikko, Lauhanen Risto (2014), "Compression drying of energy wood", Fuel Processing Technology, no. 124, pp. 286-289, ISSN 0378-3820, doi: 10.1016/j.fuproc.2014.03.016.

6 Liu Yuping, Aziz Muhammad, Kansha Yasuki, Bhattacharya Sankar, Tsutsumi Atsushi (2014), "Application of the self-heat recuperation technology for energy saving in biomass drying system", Fuel Processing
Technology, no. 117, pp. 66-74, ISSN 0378-3820, doi: 10.1016/j.fuproc.2013.02.007.

7 Hai-tao Wang, He-ming Jia (2013), "Study of Immune PID Controller for Wood Drying System", 2013 International Conference on Communication Systems and Network Technologies, pp. 827-831, ISSN 1-4673-5603, doi: 10.1109/csnt.2013.176.

8 Tian Zhongfu, Li Yuehua (2013), "Research on control system of wood drying based on BP Neural Network", Proceedings 2013 International Conference on Mechatronic Sciences, Electric Engineering and Computer $(M E C)$, no. 36-38, ISBN 4-4799-2564-3, doi: 10.1109/mec.2013.6885046.

9 Patrick Perre, Roger Keey (2014), "Drying of Wood: Principles and Practices Handbook of Industrial Drying", no. 797-846, ISBN 978-1-4665-9665-8, doi: 10.1201/b17208-44.

10 Chaikovskaya, E. E. (2015), " Rozrobka metodu pidtrymky funkcionuvannja sushyl'noi' ustanovky u skladi kogeneracijnoi' systemy [Development of methods suppot the operation of the drying plant composed of cogeneration system]", Tehnologicheskij audit i rezervy proizvodstva [Technological audit and production of reserves], no. 5/7(25), pp. 62-67, ISSN 2312-8372, doi: $10.15587 / 2312-8372.2015 .51520$.

\section{Відомості про автора (About author)}

Чайковська Євгенія Свстафіївна - кандидат технічних наук, старший науковий співробітник, Одеський національний політехнічний університет, доцент кафедри теоретичної, загальної та нетрадиційної енергетики, м. Одеca, Україна; e-mail: eechaikovskaya@ gmail.com, ORCID 0000-0002-5663-2707.

Chaikovskaya Eugene - Candidate of Technical Sciences (Ph. D.), Senior Researcher, Odessa National Polytechnic University, Associate Professor, Department of Theoretical, general and alternative energy, Odessa, Ukraine; e-mail: eechaikovskaya@gmail.com, ORCID 0000-0002-5663-2707.

Будь ласка посилайтесь на иүю статтю наступним чином:

Чайковська, Є. С. Комплексне моделювання сушильної установки у складі когенераційної системи [Текст]/ Є. Є. Чайковська // Вісник НТУ «ХПІ». Серія: Енергетичні та теплотехнічні процеси й устаткування. - Харків : НТУ «ХПІ», 2016. - № 10(1182). - С. 38-43. - Бібліогр.: 10 назв. - ISSN 2078-774X. - doi: 10.20998/2078774X.2016.10.05.

Please cite this article as:

Chaikovskaya, E. (2016), "Complex Modelling Drying Plant in the Composition of the Cogeneration System". Bulletin of NTU "KhPI". Series: Power and heat engineering processes and equipment, no. 10(1182), pp. 38-43, ISSN 2078774X, doi: 10.20998/2078-774X.2016.10.05.

Пожалуйста ссылайтесь на эту статью следуюшим образом:

Чайковская, Е. Е. Комплексное моделирование сушильной установки в составе когенерационной системы [Текст] / Е. Е. Чайковская // Вісник НТУ «ХПІ». Серія: Енергетичні та теплотехнічні процеси й устаткування. Харків : НТУ «ХПІ», 2016. - № 10(1182). - С. 38-43. - Бібліогр.: 10 назв. - ISSN 2078-774X. - doi: 10.20998/2078774X.2016.10.05

АННОТАЦИЯ Прогнозирование изменения влагосодержания воздуха в сушильной камере при измерении температуры воздуха на входе в теплообменник подогрева воздуха позволяет изменять расход нагреваемого воздуха на основе изменения частоты вращения электродвигателя воздушного вентилятора для обеспечения температурного режима сушки в сушильной камере. Согласование температурного и аэродинамического режимов сушки древесины дает возможность, например, при производстве 5,8 тыс. тонн пеллет из древесинь в год получить денежную экономию при использовании пеллетного топлива до 40 \% и снизить себестоимость производства энергии в составе когенерационной системы до (20-30) \%.

Ключевые слова: когенерационная установка, пеллетное топливо, сушильная установка, влагосодержание. 